\title{
Сопоставление результатов реконструкций напряженно- деформированного состояния программным обеспечением SGM-SIM с ранее опубликованными работами на территорию Беломорско-Кулойского плато
}

Гордеев Н.А., Сим Л.А.

Институт Физики Земли им. О.Ю.Шмидта РАН, Москва, gord@ifz.ru, sim@ifz.ru

Аннотация. Работа посвящена сопоставлению результатов сейсмических, неотектонических исследований с применением нового программного обеспечения SGM-SIM. Собраны данные по механизму очага землетрясения и направления главных осей сжатия новейшего возраста, восстановленных структурногеоморфологическим (СГ) методом Л.А.Сим (1991), по которым был подтвержден результат, полученный ранее при более мелкомасштабных исследованиях - на севере Русской плиты господствует субмеридиональное сжатие.

Гордеевым Н.А. и Молчановым А.Б. (2018) создано программное обеспечение SGM-SIM по восстановлению сдвиговых тектонических напряжений, которое основано на СГ методе Л.А. Сим. С его помощью на масштабе 1:500 000 и 1:200 000 было проведено подробное исследование современного напряженного состояния Беломорско-Кулойского региона. По известным разломам получено устойчивое субмеридиональное направление осей главных сжимающих напряжений, что согласуется с предшествующими исследованиями.

Ключевые слова: неотектоника; Беломорско-Кулойское плато; SGM-SIM; структурно-геоморфологический метод; напряженно-деформированное состояние.

\section{Comparison of the results of stress-strain state reconstructions using SGM-SIM software with previously published works on the territory of the Belomorsko-Kuloi plateau}

\author{
Gordeev N.A., Sim L.A. \\ The Schmidt Institute of Physics of the EarthRAS,Moscow,gord@ifz.ru,sim@ifz.ru
}

\begin{abstract}
The work is devoted to the comparison of the results of seismic, neotectonic studies using the new software SGM-SIM. The data on the mechanisms of earthquake foci and the directions of the main compression axes of the newest age, reconstructed by the structural-geomorphological method of L.A.Sim (1991) were collected, and the result was obtained: submeridional compression dominates in the north of the East European platform.

Gordeev N.A. and Molchanov A.B. (2018) created the SGM-SIM software for shear stress recovery, which is based on the LA method of L.A. Sim. With its help, on a scale of 1: 500,000 and 1: 200,000, a detailed study of the current stress state of the White Sea-Kuloi region was carried out. A stable submeridional direction of the axes of the main compressive stresses was obtained for the known faults. That is consistent with previous studies.

Key words: neotectonics; White Sea (Belomorsko)-Kuloi plateau; SGM-SIM; structural-geomorphological method; stress-strain state.

\section{Введение}

Одним из приоритетных направлений государственных исследований является изучение и развитие арктических и приарктических территорий. Знание неотектоники и современного напряженно-деформированного состояния необходимо для грамотного освоения территории и месторождений. На Беломорско-Куулойском плато в 2013 г. появилось первое определение механизма очага Архангельского землетрясения 2013 г., дающего возможность сравнения современных тектонических напряжений с неотектоническими, восстановленными в масштабе 1:1 000 000 структурногеоморфологическим (СГ) методом. Разработка автоматизации СГ метода (SGM-SIM) и появление механизма очага землетрясения обусловили цель исследования: произвести на более детальном уровне реконструкцию тектонических напряжений с помощью программы SGM-SIM и сопоставить
\end{abstract}


полученные данные как с результатами мелкомасштабных исследований, проведенных аналоговым вариантом СГ метода, так и с механизмом очага Архангельского землетрясения.

\section{Методика}

Структурно-геоморфологический метод Л.А. Сим основан на доминировании сдвиговых тектонических напряжений в новейший и современный этапы на платформах. Он основан на том, что разломы в осадочном чехле платформ субвертикальны; они требуют субгоризонтальных ориентировок осей сжатия и растяжения. Ориентировки оперяющих разрывов в зоне сдвига были обобщены М.В. Гзовским (1975) и применяются в СГ методе как индикаторы сдвиговых перемещений. Благодаря этим закономерным ориентировкам с помощью СГ метода определяются: ориентировка осей сжатия и растяжения в горизонтальной плоскости, кинематический тип сдвига (правый или левый сдвиг), геодинамическая обстановка формирования сдвига в осадочном чехле платформ (дополнительное растяжение или сжатие поперек сдвига).

В работе применен оригинальный способ автоматизации структурно-геоморфологического (СГ) метода реконструкции сдвиговых тектонических напряжений Л.А. Сим (Сим, 1991). Данный способ основан на применении определённого набора алгоритмов компьютерного зрения к исходным картам высот или спутниковым снимкам местности. Способ состоит из трёх этапов: на пер-

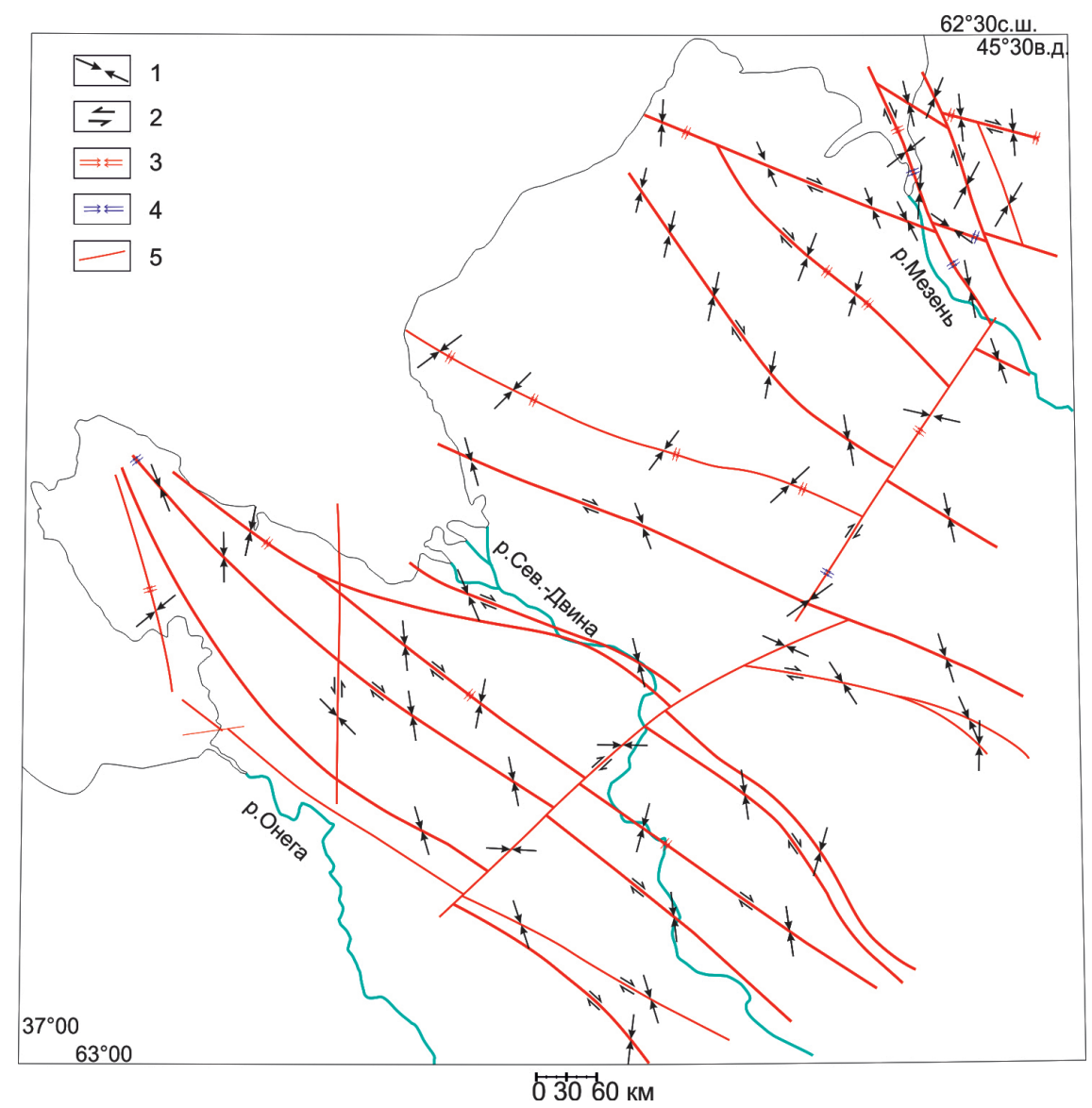

Рис. 1. Схема геодинамики Балтийско-Кулойского плато, полученная с помощью программного обеспечения SGM-SIM.

1 - субгоризонтальные оси сжатия, восстановленные методом вторичных нарушений; 2 - прогнозируемые сдвиговые смещения; 3-4 - геодинамические обстановки формирования разломов: дополнительного сжатия; 4 - дополнительного растяжения; 5 - неотектонические разломы.

Fig. 1. Geodynamic scheme of the Baltic-Kuloi plateau, obtained using the software SGM-SIM.

1 - subhorizontal compression axes, recovered by the method of secondary disturbances; 2 - predicted shear displacements; 3-4 - geodynamic settings of faults formation: additional compression; 4 - additional stretching; 5 - neotectonic faults. 


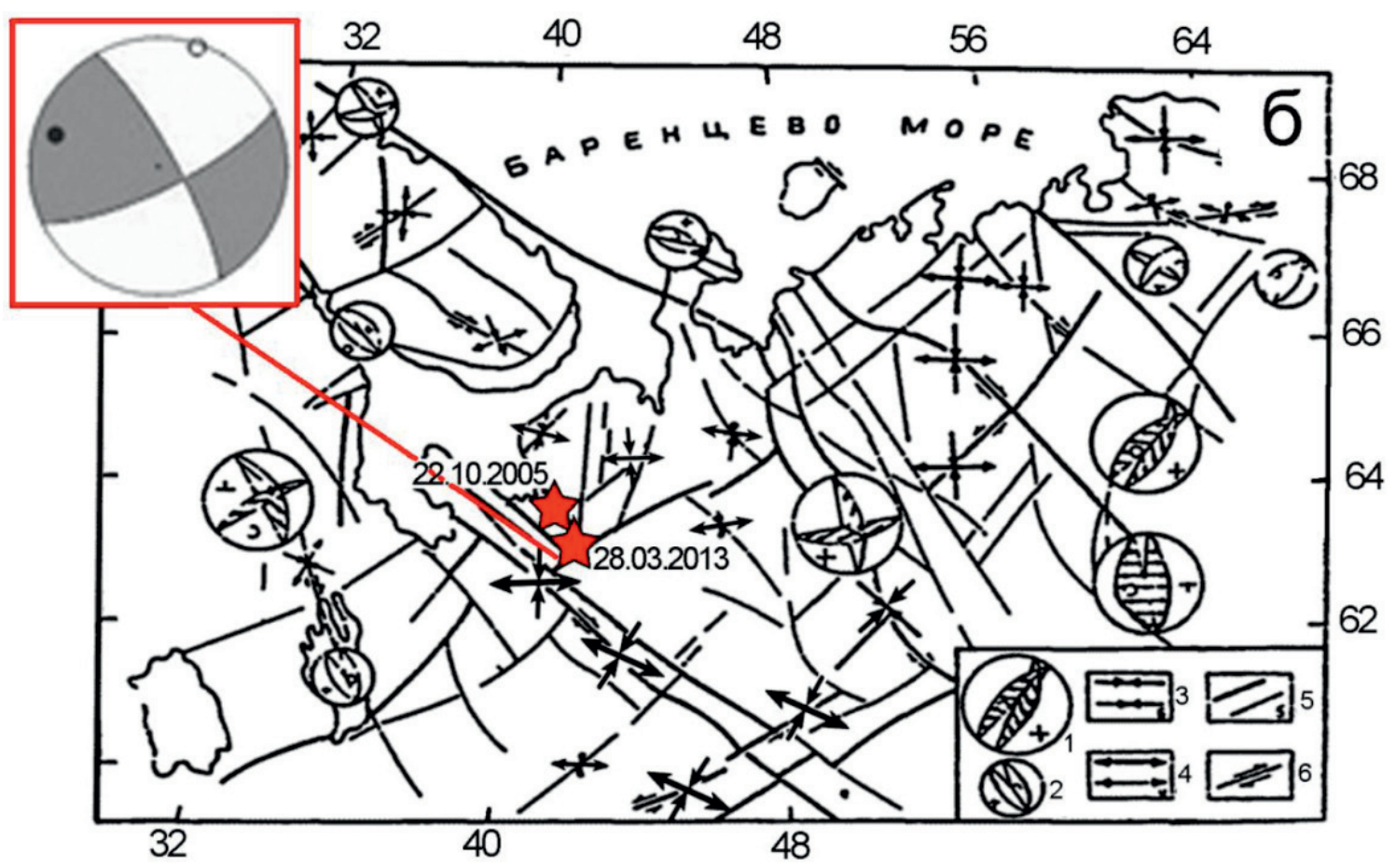

Рис. 2. Карта неотектонических напряжений европейского севера России (Сим, 2000) с эпицентрами землетрясений (звездочки) 22.10.2005 и 28.03.2013 гг., на врезке - механизм очага землетрясения 28.03.2013 г. (Конечная, 2013).

Тектонические напряжения первого (1) и второго (2) порядка, восстановленные кинематическим методом по зеркалам скольжения (стереографические проекции, верхняя полусфера, оси: сжатия - крестики, растяжения - кружки; стрелки на плоскостях максимальных касательных напряжений указывают перемещение висячего крыла); субгоризонтальные оси сжатия (3) и растяжения (4) первого и второго рангов, восстановленные СГ методом; 5 - неотектонические разломы первого и второго рангов; 6 - прогнозируемые сдвиговые смещения.

Fig. 2. The neotectonic stress map of the European north of Russia (Sim, 2000) with earthquake epicenters (asterisks) of 10/22/2005 and 03/28/2013, the inset shows the focal source mechanism of March 28, 2013 (Konechnaya, 2013). Tectonic stresses of the first (1) and second (2) order, reconstructed by the kinematic method by slip mirrors (stereographic projections, upper hemisphere, axes: compression - crosses, stretching - circles; arrows on the planes of maximum tangent stresses indicate movement of the hanging wing); subhorizontal axes of compression (3) and stretching (4) of the first and second ranks, restored by the method of secondary disturbances; 5 - neotectonic faults of the first and second ranks; 6 - predicted shear displacements.

вом этапе производится дешифрование необходимых линеаментов, на втором - поиск и измерение углов между соприкасающимися линеаментами, на третьем - сопоставление полученных ориентировок линеаментов с оперяющимися разрывами в зоне сдвига по классификации М.В. Гзовского (Гзовский, 1954, 1975).

Выделение линеаментов может быть выполнено как вручную (путём нанесения векторных фигур на участок спутникового снимка или наложения готовой схемы), так и автоматически при помощи алгоритма скелетизации бинаризованной карты высот. На следующем этапе применяется процедура поиска т.н. особых точек на скелетизованном изображении или нанесённой вручную векторной маске. Далее в точках пересечения прилегающих линеаментов и линии разлома производится измерение углов. Для этого сравнивается яркость пикселей на окружностях с центром в особой точке и радиусом, подбираемым так, чтобы шаг измерения не превышал заданной погрешности. Точки-вершины развёрнутых углов отбрасываются, а значения острых углов записываются в массив для последующей классификации по Гзовскому.

Для тестирования был выбран регион Беломорско-Кулойского плато. Территория тестирования приурочена к северу Русской плиты. Исходные карты высот были взяты из данных AsterGDEMv2. 


\section{Результаты}

Анализ разломов производился в том случае, если они были проявлены в рельефе, для этого разломы с «Карты разломов СССР...» были привязаны к космоснимкам масштаба 1:200000 и топографическим картам масштаба 1:500000. Далее по геоморфологическим признакам, таким как прямолинейные глубоко врезанные долины, крутые склоны (уступы), овражная сеть, резкие перегибы и изменения направления русел рек, определялась активность и проявленность разломов в настоящее время.

Далее к отобранным разломам применялось программное обеспечение SGM-SIM.

Проведенный анализ показывает, что в пределах исследуемой территории преобладают субмеридиональные ориентировки осей главных сжимающих напряжений. Однако при детальном рассмотрении выделяются нестабильные блоки на северо-востоке изучаемой территории в устье p. Мезень (рис. 1); здесь ориентировки осей главных сжимающих напряжений сменяются с северозападных на северо-восточные, попадаются субширотные, что говорит нам о наличии в данной области осложняющих геодинамических обстановок. По-видимому это зависит от резкой смены новейших структур, нестабильный блок находится на границе локального новейшего поднятия и в нем фиксируются обстановки дополнительного сжатия, а в центре новейшего прогиба фиксируется обстановка дополнительного растяжения. В целом субмеридиональные ориентировки подчеркивают влияние развития арктического рифта.

Использованные материалы: «Карта разломов СССР...», данные дешифрирования цифровой модели рельефа, космических снимков 1:200000 и топографических карт масштаба 1: 500000.

На Русской плите есть единственное определение механизма очага землетрясения, который был сравнен с результатами реконструкции СГ методом, сделанным Сим Л.А. (1991) (рис. 2).

Для землетрясения 28.03.2013 г. в Архангельской области вычислен механизм очага по знакам первых вступлений продольных волн (Конечная, 2013). Параметры первых вступлений были определены по 15 станциям, из них на 11 зарегистрированы волны сжатия, на 4 - волны разрежения. Тип движения по обеим плоскостям - сдвиг. Параметры плоскостей (Strike, Dip, Slip) следующие: для 1-ой плоскости $331.18,79.42,165,11$; для 2-ой плоскости 63.97, 75.37, 10.94. Вычисленный фокальный механизм очага землетрясения полностью согласуется с выводами о характерном для севера Русской плиты региональном субмеридиональном сжатии и субширотном растяжении в горизонтальной плоскости (Sim et al., 2011).

\section{Выводы}

В целом подтверждено сдвиговое поле напряжения, совпадающее с современным полем напряжения, имеющим субмеридиональную ориентацию сжатия для всей Русской плиты, которое было восстановлено Сим Л.А. (2000).

Программу можно использовать для платформенных территорий. Возраст восстановленных локальных стресс состояний и полей напряжения - новейший (неотектонический), так как по всей территории исследования развит сплошной чехол четвертичных отложений, разбитых анализируемыми линеаментами.

\section{Литература}

1. Гзовский М.В. Тектонические поля напряжений // Изв. АН СССР. Серия геофиз. 1954. № 5. С. 390-410.

2. Гзовский М.В. Основы тектонофизики. М.: Наука. 1975. 375 с.

3. Гордеев Н.А., Молчанов А.Б. Решение задачи по автоматизации структурно-геоморфологического метода реконструкции неотектонических напряжений Л.А. Сим // Современные исследования в геологии. Сборник тезисов докладов Молодежной научно-практической конференции и XVI конференции студенческого научного общества, место издания СПб: Изд-во ВВМ. 2018.

4. Карта разломов территории СССР и сопредельных стран, масштаб: 1:2500000, составлена: Министерство геологии СССР. 1980.

5. Конечная Я.В. Анализ сейсмичности в районе архипелага Земля Франца-Иосифа // Вестник САФУ. Сер. Естественные науки. Архангельск: САФУ. 2013. № 1. С. 10-13.

6. Сим Л.А. Изучение тектонических напряжений по геологическим индикаторам (методы, результаты, рекомендации) // Изв. ВУЗов. геол. и разв. 1991. № 10. С. 3-22.

7. Сим Л.А. Влияние глобального тектогенеза на новейшее напряженное состояние платформ Восточной Европы // М.В. Гзовский и развитие тектонофизики. М.: Наука. 2000. С. 326-348. 